\title{
VIGILÂNCIA AOS EFEITOS DA NOVA FRONTEIRA AGRÍCOLA: UMA ANÁLISE PARTICIPATIVA SOCIOAMBIENTAL E DE RISCO À SAÚDE DAS COMUNIDADES EXPOSTAS À POLUICCÃO ATMOSFÉRICA EM ÁREAS DE TRANSIÇÃO DE CERRADO-AMAZÔNIA, SUDESTE DO PARÁ
}

\author{
Thiago Fernandes \\ Universidade Federal Rural da Amazônia (UFRA), Parauapebas, PA, Brasil \\ Pós-graduação em Ciências Ambientais (UNEMAT)
}

thiago.ufra.pa@gmail.com

Sandra de Souza Hacon

Escola Nacional de Saúde Pública (ENSP), Fundação Oswaldo Cruz (FIOCRUZ), Rio de Janeiro, RJ, Brasil

Pós-graduação em Ciências Ambientais (UNEMAT)

sandrahacon@gmail.com

Jonathan Willian Zangeski Novais

Universidade de Cuiabá (UNIC), Campus Barão, Cuiabá, MT, Brasil

Pós-graduação em Ciências Ambientais (UNIC)

jonathan.novais@kroton.com.br

\begin{abstract}
RESUMO
O sudeste paraense é uma das mesorregiões de fronteira agrícola da Amazônia brasileira que contextualiza uma ampla história de expansão territorial baseada em conflitos sociais. Desse modo, objetivou-se, com esta pesquisa, identificar os municípios em situação de risco ambiental e epidemiológico e seus problemas socioambientais e de impacto à saúde em comunidades expostas à poluição atmosférica. $O$ método de trabalho baseou-se na análise dos relatórios sobre os Instrumentos de Identificação de Municípios de Risco (IIMR). Para o diagnóstico participativo socioambiental, realizou-se a aplicação de questionários sociodemográficos e condução de uma oficina temática, fundamentando-se na abordagem de intervenção da árvore de problemas. Pelo diagnóstico de risco, 64,1\% dos municípios da mesorregião se encontram em situação de alta vulnerabilidade ambiental e epidemiológica, expondo a RI Lago do Tucuruí como a região mais susceptível devido aos impactos decorrentes da expansão das matrizes econômicas, maiormente pela agropecuária e hidrelétrica. A percepção dos atores sociais esclareceu uma falta de diálogo com as comunidades de faixa de fronteira sobre os riscos iminentes das ações progressivas do agronegócio, bem como a falta de manutenção das políticas públicas que tratam de saúde e ambiente em defesa de uma melhor qualidade de vida nas comunidades.
\end{abstract}

Palavras-chave: Risco ambiental. Saúde pública. Agronegócio. Sociedade.

\section{VIGILANCE TO THE EFFECTS OF THE NEW AGRICULTURAL BORDER: A PARTICIPATORY SOCIO-ENVIRONMENTAL AND HEALTH RISK ANALYSIS OF COMMUNITIES EXPOSED TO ATMOSPHERIC POLLUTION IN TRANSITION AREAS OF THE CERRADO-AMAZÔNIA, SOUTHEAST OF PARÁ}

\begin{abstract}
The Southeast Para is one of the agricultural frontier regions of the Brazilian Amazon that contextualizes a broad history of territorial expansion based on social conflicts. Thus, this research aimed to identify municipalities at environmental and epidemiological risk and their socio-environmental problems and health impact in communities exposed to air pollution. The work method was based on the analysis of the reports on the Instruments for the Identification of Municipalities at Risk (IIMR). For the socio-environmental participatory diagnosis, socio-demographic questionnaires were applied and a thematic workshop was conducted, based on the intervention approach of the problem tree. According to the risk diagnosis, $64.1 \%$ of the municipalities in the mesoregion are in a situation of high environmental and epidemiological vulnerability, exposing the RI Tucuruí Lake as the most susceptible region due to the impacts resulting from the expansion of economic matrices, mainly by agriculture and cattle raising and hydroelectric power. The perception of social actors clarified a lack of dialogue with frontier communities about the imminent risks of progressive agribusiness actions, as well as the lack of maintenance of public policies dealing with health and the environment in defense of a better quality of life in the communities.
\end{abstract}

Keywords: Environmental risk. Public health. Agribusiness. Society.

Caminhos de Geografia Uberlândia-MG v. 21, n. 78

p. $270-289$

Página 270 


\section{INTRODUÇÃo}

A expansão da fronteira agrícola e das atividades pecuaristas teve início em meados da década de 1970 e foi considerada um movimento característico dos setores do agronegócio brasileiro, combinando os avanços da modernização agrícola com a invasão e ocupação de terras entre as fronteiras regionais do bioma Amazônico. No mesmo período, a ampliação de área ocupada foi intensificada nas regiões de transição entre os biomas Cerrado e Amazônia, induzindo ao detrimento total de $52 \%$ do bioma Cerrado, atingindo áreas de preservação florestal no Sudeste do Pará, Sul do Maranhão e Norte do Tocantins, colocando prementes intimidações para seu futuro e para os contornos de vida tradicionais de seus habitantes (PITTA; VEGA, 2017).

Diante disso, Xavier et al. (2011) comentam que a chamada expansão agrícola surgiu influenciada pelos preços dos grãos e da venda do gado de corte, o que levou à maior centralização de terras que, por sua vez, foram apassivadas pelas demarcações arbitrárias, impostas sem as devidas fiscalizações governamentais, gerando conflitos entre os grandes fazendeiros e as comunidades rurais, ribeirinhas, quilombolas e indígenas. Para Silva e Miziara (2011), com os avanços dessa nova fronteira, os ataques e a violência no campo aumentaram consideravelmente, e os povos tradicionais sofrem pelo não reconhecimento de seus direitos territoriais, baseados mais nos costumes e na ocupação continuada do solo ao longo das gerações do que em documentos legais emitidos pelo Estado, em uma região que se caracteriza pela irregularidade fundiária e pela modalidade de desenvolvimento capitalista.

Com o afrouxamento das políticas de incentivos fiscais e industriais, levou-se à utilização intensiva de recursos como a água e o solo, suscitando a transformação da paisagem mediante a introdução não só das lavouras, mas das diversas infraestruturas produtivas e de escoamento indispensáveis à realização dessas atividades, como estradas e hidrovias (PEREIRA et al., 2018). Em 2015, como uma forma de coroar todo esse processo de expansão, o governo brasileiro criou a região especial conhecida como MATOPIBA (acrônimo criado com as iniciais dos Estados do Maranhão, Tocantins, Piauí e Bahia), situada na região Norte do Cerrado (onde ainda existe grande parte de sua cobertura vegetal original), o que daria o marco legal imperioso a uma ocupação ainda mais intensiva do bioma, por parte do capital financeiro e agroindustrial, visando à exportação de commodities agrícolas e minerais (PEREIRA; PAULI, 2016).

Apesar da nova perspectiva mundial de gestão socioambiental participativa, que contempla a percepção e a participação de atores sociais potencialmente afetados por problemas locais de saúde e ambiente na avaliação e tomada de decisão (PORTO, 2012), esta parece se distanciar da produção científica das ciências ambientais e da concretude de ações políticas no cenário nacional (LOEWENSON, 2013; SERAPIONI, 2014). Isto posto, tem-se como exemplo o estudo socioparticipativo realizado em 2018 por FIAN-International, Rede Social de Justiça e Direitos Humanos e Comissão Pastoral da Terra (CPT), Organização pelo Direito Humano à Alimentação e à Nutrição Adequadas e demais parceiros institucionais e não governamentais, que destaca com exatidão que a população local nessa região de fronteira agrícola sofre com as graves consequências do desmatamento, da perda da biodiversidade e da contaminação generalizada do solo, da água e dos alimentos por insumos e agrotóxicos e, principalmente, com a poluição atmosférica, causada pelo processo de ocupação urbanístico desenfreado, motivado pelas matrizes econômicas de desenvolvimento na região. Portanto, com base em todos os fatos registrados, o presente estudo buscou identificar os municípios em situação de risco ambiental e epidemiológico e seus problemas socioambientais e de ímpeto à saúde em comunidades expostas à poluição atmosférica em áreas de fronteira agrícola no Sudeste da Amazônia paraense.

\section{METODOLOGIA}

\section{Área de abrangência do estudo}

A área de estudo abrangeu os 39 municípios que formam geograficamente a mesorregião do Sudeste do Pará. O Estado paraense e, em especial, a mesorregião Sudeste, a partir do final da década de 1960, iniciaram uma longa trajetória de crescimento econômico e de integração com o resto do país e o exterior (SANTOS, 2017). De acordo com a história descrita na obra de Silva e Silva (2008), o Sudeste da Amazônia paraense sofreu uma intensiva pressão por transformação social, econômica e ambiental ao longo das décadas de 1970 e 1980, período que coincidiu com a ampliação das ações

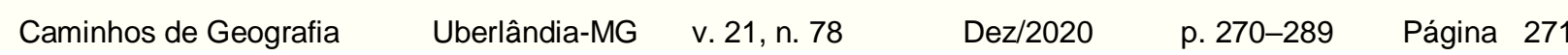


do Estado brasileiro para levar a um forte crescimento do PIB paraense, ocorrendo, a partir de 1980, taxas anuais superiores às apresentadas pela economia brasileira (MENDES, 2004).

Segundo o Instituto Brasileiro de Geografia e Estatística (2010), a mesorregião possui uma área total de 297.344,257 km², com uma população de 1.647 .570 habitantes, e municípios como Conceição do Araguaia, Marabá, Paragominas, Parauapebas, Redenção e Tucuruí (PA) destacam-se no cenário nacional e internacional devido à produção de energia, concentração de empreendimentos madeireiros, expansão da pecuária de corte e fácil acesso às matérias-primas de minero-metalúrgicas (BRITO; SILVA, 2020).

\section{Procedimentos de coleta de dados}

A coleta e operacionalização dos dados referentes a ambiente e saúde foram processadas junto ao banco de informações do Programa de Vigilância em Saúde Ambiental de Qualidade do Ar no Estado do Pará, conhecido popularmente como VIGIAR, que foi institucionalizado como uma metodologia aplicada à vigilância para riscos ambientais e epidemiológicos validada pelo Ministério da Saúde. Segundo a Companhia Ambiental do Estado de São Paulo (2012), o programa VIGIAR baseia-se na nova Resolução CONAMA no 491 de 19/11/2018 (Revoga a Resolução CONAMA no 03/1990 e os itens 2.2.1 e 2.3 da Resolução CONAMA no 05/1989), em que estabelece os novos padrões nacionais de qualidade do ar ambiente.

Para Costa et al. (2014), a formatação desse programa no Estado do Pará atende à legislação, às normas e aos procedimentos preconizados pelo Ministério da Saúde, além de contar com recursos auxiliares, como é o caso dos Instrumentos de Identificação de Municípios de Risco (IIMR), que foi idealizado como uma ferramenta que contém informações ambientais, como as indústrias de extração e de transformação, frota veicular e focos de calor, e, ainda, informações de saúde, como taxas de mortalidade e internações por Doenças do Aparelho Respiratório (DAR). Villard (2015) complementa ao citar que os dados constantes no IIMR possibilitam o planejamento de ações preventivas e auxiliam na adoção de medidas corretivas, além de abrir espaço para discussão com os órgãos ambientais locais.

A aplicação do IIMR foi inserida na Programação de Ações de Vigilância em Saúde (PAVS) no ano de 2007 e, em 2011, o IIMR passou a ser disponibilizado para cada uma das 27 Unidades Federativas (UF) por meio do website Painel de Informações em Saúde Ambiental e Saúde do Trabalhador (PISAST). Para concretização deste estudo, foi considerada a avaliação das informações ambientais e de saúde extraídas diretamente de boletins técnicos informativos entre os anos de 2011 e 2017. Considerou-se esse curto período em virtude de o Estado do Pará ter participado com $100 \%$ de seus municípios no preenchimento do IIMR em 2017 (SANTOS, 2013).

A identificação dos municípios em risco para a vigilância em saúde de populações expostas à poluição atmosférica foi feita por meio do levantamento dos indicadores de ambiente, como fontes fixas (indústrias extrativistas e de transformação), fontes móveis (frota veicular) e queima de biomassa (focos de calor) e de saúde, sendo as doenças do aparelho respiratório (CID10, Cap. X) responsáveis pelas taxas de internação e mortalidade. Foi realizado um levantamento de todos os indicadores, com informações para cada um dos 39 municípios, de forma individual, cronológica e categorizada, criando assim um banco de dados abrangente.

\section{INDICADORES AMBIENTAIS}

\section{Fontes fixas e móveis de poluição atmosférica}

Os dados e as informações sobre fontes fixas de poluição do ar (indústrias extrativas e de transformação) foram extraídos gratuitamente dos websites da Fundação Amazônia Paraense de Amparo à Pesquisa (2017) e do Ministério do Trabalho e Emprego - MTE/RAIS (2017). Subsequentemente, os dados e as informações referentes às fontes móveis de poluição do ar (frotas veiculares e focos de calor) foram também extraídos gratuitamente dos websites do Departamento Nacional de Trânsito (2017) e do Instituto Nacional de Pesquisas Espaciais (2017). Acrescenta-se que, para cada variável citada, foi criada uma coluna específica dentro do banco de dados, perfazendo, assim, as análises para cada um dos 39 municípios da área em estudo e para o Estado do Pará. 


\section{INDICADORES DE SAÚDE}

\section{Taxas de internação e de mortalidade por agravos respiratórios}

Os dados referentes a internações e óbitos por agravo respiratório foram extraídos gratuitamente do website do Departamento de Informática do Sistema Único de Saúde do Ministério da Saúde (2017). Estes dados são referentes a cada um dos 39 municípios da área de estudo e para o Estado do Pará. Após a execução de todos os processos (extração e tabulação), foi possível calcular a taxa de internação e de mortalidade por agravos respiratórios para toda a população da mesorregião utilizando as Equações (1) e (2) e seguindo as mesmas orientações dadas pelo Ministério da Saúde (2012).

$$
\begin{aligned}
& T I(\%)\left(\frac{\text { Número de internações por agravos respiratórios no ano }}{\text { Populaçâo total do municipio no ano }}\right) \times 10^{3} \\
& T M(\%)\left(\frac{\text { Número de óbitos por agravos respiratórios no ano }}{\text { População total do municipio no ano }}\right) \times 10^{3}
\end{aligned}
$$

Em que: TI (\%) é a Taxa de Internação, TM (\%) é a Taxa de Mortalidade e a constante 3 significa que, a cada 1.000 habitantes, haverá X casos de internações para esse grupo de doenças (J00 a J99).

Para determinar as taxas de internação e de mortalidade por agravos respiratórios para o Estado do Pará, foram utilizadas as mesmas equações, porém, substituindo os valores das variáveis investigadas em cada município pelos da totalidade anual registrada no Estado.

\section{Análises e interpretações dos dados}

Os dados e as informações foram organizados em planilhas eletrônicas e submetidos à análise por pontuação e por peso-indicador. Foi atribuída pontuação a cada um dos indicadores, obtendo pontuação específica para cada um dos 39 municípios, seguindo a mesma metodologia do Ministério da Saúde (2012) e embasados nos mesmos procedimentos metodológicos que foram aplicados por Peres et al. (2009), Freitas et al. (2013) e Villardi (2015) em estudos sobre a avaliação dos indicadores previstos no IIMR para alguns Estados brasileiros. À vista disso, o Fator de Risco do Estado foi calculado a partir da média aritmética de cada umas das variáveis, apropriando-se, como critério de pontuação final, a lógica dada por valores finais, conforme mostra a Tabela 1.

Tabela 1 - Classificação do Risco em Saúde e Ambiente.

\begin{tabular}{cc}
\hline Valores & Fator de Risco \\
\hline Valores $>$ que o valor do Estado $\rightarrow$ & Alto \\
Valores $>$ ou $<$ que o valor do Estado $\rightarrow$ & Médio \\
Valores $<$ que o valor do Estado $\rightarrow$ & Baixo \\
\hline Fonte - Peres et al. (2009), Freitas et al. (2013), Villardi (2015) e Ministério da Saúde (2012).
\end{tabular}

Por fim, todo o processamento de espacialização temporal feito com os dados foi realizado no

\begin{tabular}{|c|c|c|c|c|c|}
\hline Caminhos de Geografia & Uberlândia-MG & v. 21, n. 78 & Dez/2020 & p. 270-289 & Página 273 \\
\hline
\end{tabular}
software livre QGIS, versão 3.4. 


\section{Método para intervenção com os atores sociais}

Refere-se a um estudo de caráter exploratório, ancorado na abordagem estrutural da Teoria das Representações Sociais (TRS), à qual submerge como a essência de um objeto que, a priori, reflete aquilo que está sendo averiguado e a vivência dos sujeitos, que faz referência àqueles que concebem esse objeto investigado (MOSCOVICl, 2011). No caso deste estudo, os sujeitos são representantes da sociedade civil organizada, das classes política, estudantil, campesina, rural, assentada e/ou indígena, e o objeto é a relação direta e indireta entre as forças motrizes do desenvolvimento econômico do Sudeste paraense e a poluição atmosférica como agravo à saúde humana e ambiental.

A população do estudo caracteriza-se como diversificada (sem critérios para gêneros, sexo, etnia e outros), embora os participantes fossem residentes dos municípios de Parauapebas, Canaã dos Carajás, Curionópolis, Eldorado dos Carajás, Marabá, Conceição do Araguaia, Floresta do Araguaia, Rio Maria, Santa Maria das Barreiras, São Domingos do Araguaia, Santana do Araguaia e Rondon do Pará, situados na mesorregião Sudeste do Pará. A amostra consistiu em 41 indivíduos. Os critérios de inclusão foram: ter idade igual ou superior a 18 anos e residir em um dos municípios identificados acima e que são classificados como de "alto risco" há mais de 1 ano. Por sua vez, os critérios de exclusão foram: indivíduos que não são desses municípios, estrangeiros e/ou pessoas que migraram há menos de 1 ano.

O processo de amostragem foi probabilístico, por conglomerado de aproximação à sede em que se reuniram os atores sociais para a coleta de dados, que, neste estudo, foi o município de Parauapebas (PA) por questões de centralização de recursos de pessoal, de materiais e de espaço para a oficina. Foi respeitado como área censitária um raio de até $500 \mathrm{~km}$ da sede, em virtude da amostragem, com probabilidade proporcional aos demais municípios da mesorregião. Neste estudo, foram priorizados os municípios que fazem fronteira territorial agrícola com os Estados de Tocantins (TO), Mato Grosso (MT) e Maranhão (MA). Tal procedimento manteve a intenção da autoponderação da amostra final de municípios igual ou > que $30 \%$. A coleta de dados foi realizada a partir de uma ação de extensão via oficina de formação continuada, registrada institucionalmente na Pró-reitoria de Extensão da Universidade Federal Rural da Amazônia (UFRA), com número de processo CR001-2019, planejada e desenvolvida no mês de junho de 2019.

Por isso, como forma de materialização da representação coletiva, foi aplicada a metodologia conhecida como árvore de problemas, adicionando ludicamente o problema central como "tronco", as causas que levam ao acontecimento desse problema como as "raízes" e os efeitos negativos das causas como "galhos e folhas", seguindo o mesmo enfoque usado por Moniz et al. (2017) em um estudo sobre percepção socioambiental e de saúde com comunidades expostas à poluição do ar no entorno de um complexo petroquímico no Estado do Rio de Janeiro (RJ). Para os autores, essa abordagem se caracteriza pela construção derivada do processo participativo, com traços marcantes de flexibilidade e de adaptabilidade às mais distintas situações. A integração dos elementos marco lógico, instrumental, técnicas de moderação e de visualização das escolhas coletivas e sistemática básica de convivência é a marca distintiva do método da árvore (SERAPIONI, 2014).

Prontamente, após a formação, foram construídos painéis lúdicos para os quatro cenários citados nesse contexto como matrizes econômicas de desenvolvimento, formando assim Grupos de Trabalho nomeados como: GT1 - Mineração; GT2 - Produção de Energia; GT3 - Pecuária; e GT4 - Extração de Madeira, construídos conforme a percepção de cada grupo. A posteriori, foi dado enfoque à apresentação coletiva. Foi sugerido que, durante a explanação, cada GT destacasse no painel, com um asterisco $\left({ }^{*}\right)$, duas "causas-efeitos" que representassem a percepção coletiva, tornando-se os termos indutores, seguindo a mesma abordagem feita por Moura et al. (2017) e Coutinho e Bú (2017). Essa assinalação feita pelos atores sociais, no material portfólio, garantiu o êxito do Teste de Associação Livre de Palavras (TALP), que foi utilizado para apreensão de informações norteadoras da estrutura das Representações Sociais (RSs) juntamente com os questionários com dados sobre 0 perfil sociodemográfico. A análise dos questionários sociodemográficos envolveu a descrição estatística básica (médias e percentuais), com auxílio do programa informático Excel, versão 2016.

Os dados empíricos coletados acerca dos painéis foram categorizados e organizados em um banco de dados, formando o corpus que foi analisado com o auxílio do aplicativo Voyant Tools, cuja função é calcular e informar a frequência simples (f.) de ocorrência de cada palavra. Nessa análise, o ponto de corte utilizado foi uma frequência igual ou acima do valor 3 . A análise estrutural foi complementada levando em consideração a frequência de evocação, possibilitando identificar, assim, os termos da estrutura da Representação Social (RS) no estudo. Por fim, realizou-se a discussão embasada em 
estudos sobre a temática, criando uma árvore lúdico-ilustrativa para cada um dos cenários econômicos, a fim de destacar os aspectos cognitivos no que concerne às RSs dos sujeitos.

A investigação foi previamente aprovada pelo Comitê de Ética em Pesquisa da Universidade do Estado de Mato Grosso Carlos Alberto Reyes Maldonado - UNEMAT, parecer CEP № 3.393.614. Salienta-se que os sujeitos participaram voluntariamente da pesquisa. Todos preencheram e assinaram o Termo de Consentimento Livre e Esclarecido, atendendo à Resolução 466/2012 do Ministério da Saúde, Conselho Nacional de Saúde, Comissão Nacional de Ética em Pesquisa, bem como às diretrizes e normas que regem pesquisas envolvendo seres humanos.

\section{RESULTADOS E DISCUSSÃO}

Com a espacialização dos dados segundo o risco ambiental e epidemiológico (poluição atmosférica), pode-se observar, pela Figura 1, que 25 desses municípios foram classificados como de "Alto Risco", perfazendo 64,1\%; 6 foram classificados como de "Médio Risco", representando 15,4\%; e, por fim, 8 foram classificados como de "Baixo Risco", concebendo $20,5 \%$ do total analisado.

De acordo com o último boletim informativo do IIMR - Programa VIGIAR, construído em parceria com a Secretaria de Saúde Pública do Estado do Pará (SESPA), com a Diretoria em Vigilância em Saúde do Pará (DVS) e a Fundação Amazônia Paraense de Amparo à Pesquisa (FAPESPA) a partir de dados analíticos e sociodemográficos, entre 2011 e 2017 foram contabilizadas, na mesorregião Sudeste, 91 indústrias extrativistas de minerais metálicos e não metálicos e 1.284 indústrias de transformação, abarcadas nesse contexto como fontes fixas de poluição atmosférica. Considerando as dimensões das variáveis em estudo, municípios como Curionópolis, Marabá, Parauapebas, São Félix do Xingu e Tucumã (PA) se destacaram na indústria extrativista de minerais metálicos e não metálicos, representando $56 \%$ do total de indústrias desse segmento. Salienta-se que no Estado do Pará não há proeminência de atividades de extração de carvão mineral e de petróleo.

Figura 1 - Identificação geral dos municípios em situações de riscos à exposição da poluição atmosférica no território da mesorregião Sudeste paraense, Brasil.

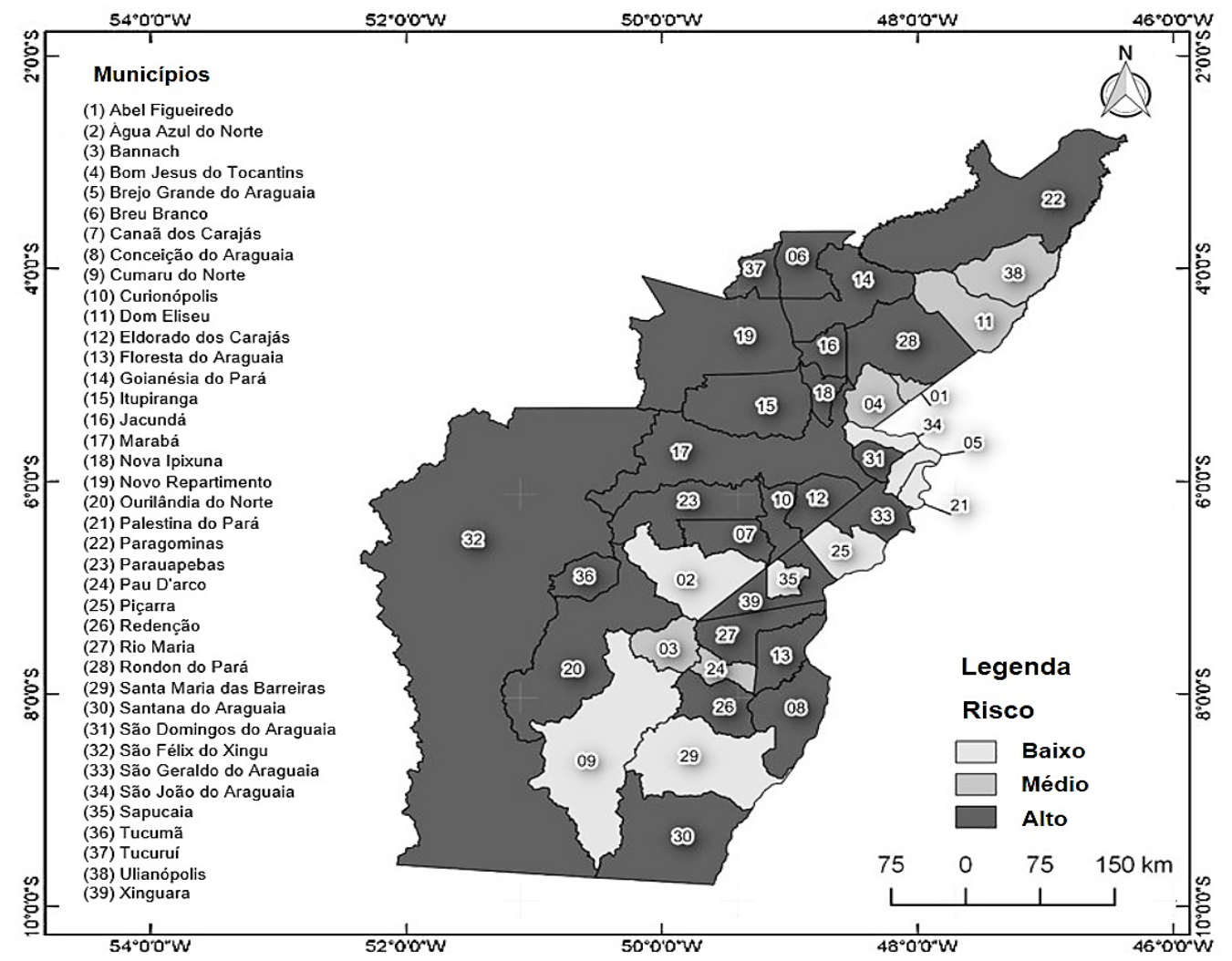

Fonte - Elaborado pelos autores a partir de dados coletados em boletins técnicos e agências governamentais. 
Ao analisar o desempenho da indústria de transformação, destaca-se uma série de atividades produtivas que encargam segmentos importantes, como produção de óleos e gorduras vegetais e animais, torrefação de café, curtimento de couro, celulose, metalúrgica e siderúrgica, dentro outros. $A$ priori, para o caso da mesorregião, os municípios em destaque foram Goianésia do Pará, Jacundá, Marabá, Paragominas, Redenção, Rondon do Pará, Tucuruí e Xinguara (PA), representando 70\% do total da indústria de transformação. Monteiro (2005) e Lobato e Emmi (2014) citam que o processo de valorização industrial de recursos minerais, entendido como a agregação de valor e conversão de recursos minerais em mercadoria na Amazônia oriental brasileira, iniciou-se com a exploração das reservas de minério de manganês da Serra do Navio, onde hoje é o Território Federal do Amapá (AP), e foi se estendendo por toda a região Norte brasileira. Paralelamente, também foi no âmbito do Projeto Grande Carajás (Projeto PGC) que se implementou a valorização da indústria de transformação no Sudeste paraense, nos anos 1980 e 1990, solidificando sua base estruturante no município de Parauapebas (PA) com atividades de extração do minério de ferro na Floresta Nacional de Carajás (Flona Carajás/PA).

$\mathrm{Na}$ concepção de Becker (2010), esse projeto, cuja condução havia sido assumida ainda na década de 1970 pela antiga Companhia Vale do Rio Doce, hoje Vale S/A, montou uma gigantesca estrutura envolvendo, além da Company Town na Serra dos Carajás, um sistema que abarca minas, instalações de beneficiamento e um pátio de estocagem, instalações portuárias e a Estrada de Ferro Carajás, cujo dimensionamento registra mais de 890 quilômetros de extensão e interliga a Serra dos Carajás ao terminal marítimo da Ponta da Madeira, em São Luís (MA). Esse movimento foi impulsionado pela descoberta de áreas em potencial para exploração de minerais, considerada o ápice do processo de desenvolvimento industrial, revolucionando a matriz econômica de vários municípios do Estado do Pará devido às chamadas compensações ambientais, regidas pela atual Lei no 13.668 , de 28 de maio de 2018. Entretanto, como em toda e qualquer mudança que aconteça em regime de intensa exploração, há ocorrências de ações que intensificam agravos ambientais e sociais, por exemplo, a alta frequência da imigração de ativos humanos, as ocupações e apropriações indevidas em áreas urbanas e rurais, que, nessa fase da história, geraram conflitos culturais com as comunidades e os povos tradicionais incitados pelo sistema capitalista.

Com relação às fontes móveis de poluição atmosférica, o boletim esclarece que a poluição do ar tem se intensificado em toda área de abrangência da Amazônia brasileira, atingindo diretamente a saúde da população humana. Vale destacar, no entanto, que o Estado do Pará estadeou aumento significativo da frota veicular, notavelmente, em municípios acima de 100 mil habitantes, ocasionando problemas urbanos de trânsito e de mobilidade e aumento da emissão de poluentes, o que corrobora com a incidência de casos de problemas de saúde por doenças do aparelho respiratório (DAR). Para a Organização Mundial de Saúde (2018), as chamadas fontes móveis, constituídas principalmente por veículos automotores e queimadas florestais, são responsáveis pela emissão de $90 \%$ de poluentes na atmosfera. Em 2017, o Estado do Pará registrou 1.428.370 veículos automotores, estabelecendose na primeira colocação da região Norte e na décima segunda colocação em nível nacional (DENATRAN, 2017). Segundo o mesmo departamento regulamentador, a mesorregião em estudo fechou o mesmo ano com 458.942 veículos automotores com registro ativo, com destaque para os municípios de Xinguara (21.629), Tucuruí (24.608), Paragominas (28.439), Redenção (47.011), Parauapebas (62.340) e Marabá (88.100), representando $60 \%$ da frota veicular total ativa.

Habermann et al. (2011) comentam que, durante as duas últimas décadas, vem sendo observada uma queda na emissão de poluentes por veículos. Apesar disso, as fontes móveis ainda se constituem uma das principais emissoras de poluentes atmosféricos nas áreas urbanas. No Brasil, as três maiores áreas metropolitanas (São Paulo, Rio de Janeiro e Belo Horizonte, no Sudeste brasileiro) somam $45 \%$ da frota nacional de veículos. O aumento da frota veicular também leva a uma menor capacidade de fluidez no trânsito, o que acarreta maior tempo despendido em congestionamentos, aumenta a queima de combustíveis e gera mais poluição (PAHO, 2005). Para o INPE (2018), no ano de 2017, foram contabilizados 49.770 focos de calor no Estado do Pará (PA), colocando-o em primeiro no ranking dos Estados com maiores quantidades de focos pela região Norte do Brasil. Segundo Almeida e Souza (2016), comunidades Xavantes como os Bororos tiveram sua cultura alterada de forma mais intensa pelos não indígenas de cultura ocidental. Dentre essas alterações, destaca-se a mudança no sistema de limpeza da área, que antes era feita manualmente, com o auxílio do fogo; além disso, as roças não eram destocadas. Porém, com a introdução das máquinas, na década de 1970, a limpeza passou a ser feita mecanicamente. As práticas agrícolas são

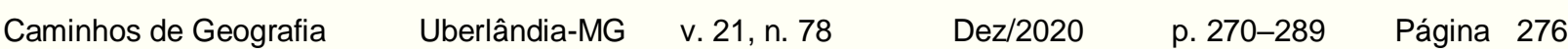


semelhantes às práticas adotadas pelos "brancos", seguindo os modelos tradicionais não indígenas (PINTO; GARAVELLO, 2002).

Lopes e Albuquerque (2018) destacam que a associação entre ocupação intensiva, desmatamento, focos de calor e fogo merece destaque devido aos diferentes contextos em que podem surgir. Para Fonseca-Morello et al. (2017), as principais causas de fogo na Amazônia são queimadas originadas de desmatamentos, queimadas de manutenção e limpeza de pastagens, lavouras e capoeiras e incêndios florestais rasteiros oriundos de queimadas descontroladas que invadem a floresta. Isto posto, o boletim informático construído por Fonseca et al. (2019) e divulgado pela Imazon cita que, somente em julho de 2019, o Sistema de Alerta de Desmatamento detectou 1.287 quilômetros quadrados de área desmatada na Amazônia Legal, um aumento de $66 \%$ em relação a julho de 2018 , quando o desmatamento somou 777 quilômetros quadrados. Em julho de 2019, o desmatamento ocorreu no Pará (36\%), Amazonas (20\%), Rondônia (15\%), Acre (15\%), Mato Grosso (12\%) e Roraima (2\%), sendo que a maioria (69\%) do desmatamento ocorreu em áreas privadas ou sob diversos estágios de posse. O restante do desmatamento foi registrado em assentamentos (24\%), unidades de conservação (4\%) e terras indígenas (3\%).

Todavia, segundo o mesmo boletim, essas evidências sinalizam um alerta ao Estado do Pará (PA), por ser um dos mais afetados, o que levou as Organizações Internacionais de Conservação a classificá-lo como de nível crítico. Para a FAO - Organização das Nações Unidas para a Alimentação e a Agricultura (2010), os agravos causados pelas queimadas estão cicatrizados no ecossistema amazônico, que já demonstra, desde a última década, alguns desfechos como desertificação e descompactação do solo, principalmente em áreas sentinelas como unidades de conservação, assentamentos e terras indígenas. De tal modo, em 2017, somente a mesorregião do Sudeste paraense registrou 6.747 focos de calor, com destaque para os municípios de São Félix do Xingu (953), Santa Maria das Barreiras (528), Novo Repartimento (464), Santana do Araguaia (453) e Cumaru do Norte e Paragominas (ambos com 423 focos de calor), representando $48 \%$ do total de registros. Ressalta-se que, dentre os municípios citados, alguns fazem fronteira com o Estado de Mato Grosso e Tocantins, como é o caso de Santa Maria das Barreiras e Santana do Araguaia (PA), onde são mantidas importantes florestas e áreas de preservação permanente, caso do município de São Félix do Xingu (PA).

Para Costa e Reis (2017), essa região em específico é considerada uma nova fronteira amazônica de desenvolvimento para o agronegócio, que tem atraído diversos projetos de colonização e de exploração dos recursos naturais embasados no discurso voltado para o desenvolvimento econômico, porém sem uma preocupação iminente com os impactos socioambientais decorrentes de tais ocupações. Para os autores, essa mesma área vem sendo palco de confrontos abusivos devido à colonização da APA Triunfo do Xingu (APATX), que, criada em 2006, situa-se como uma unidade de conservação do grupo de uso sustentável, com uma área de aproximadamente 1.700 .000 hectares ocupando parte dos municípios de Altamira e São Félix do Xingu (PA), e vem sofrendo, nos últimos cinco anos, uma enorme pressão antrópica, principalmente pelas atividades madeireira e pecuária, somada aos inúmeros conflitos pela posse de terras. Novamente segundo o Imazon, somente em julho de 2019, a APATX foi uma das Unidades de Conservação (UC) no Brasil que padeceu intensamente com o desmatamento acelerado e desordenado, registrando $3 \mathrm{~km}^{2}$ de área desmatada, posicionando-se em primeiro no ranking de UCs mais atingidas no território brasileiro.

Segundo o Censo Agropecuário realizado pelo IBGE em 2017, o Estado do Pará situou-se na 5a posição entre as Unidades Federativas com maior efetivo de bovinos do Brasil (20,6 milhões de cabeças), tendo o município de São Félix do Xingu (PA) como líder do ranking de maior efetivo de bovinos do Brasil, com 2,2 milhões de cabeças. Em se tratando dos riscos epidemiológicos, foram destacados alguns municípios que, em tese, exibiram taxas elevadas de internações e óbitos por DAR. Segundo dados da Organização Mundial de Saúde (2018), estas doenças representam cerca de $8 \%$ do total de mortes em países desenvolvidos e $5 \%$ em países em desenvolvimento. No Brasil, são responsáveis por aproximadamente $16 \%$ de todas as internações (MARINHO et al., 2016). Porém, em grupos mais vulneráveis como as crianças, as DAR compreendem mais de $50 \%$ das internações hospitalares (NASCIMENTO et al., 2017). Não obstante, em 2017, foi apurado um total de 71.922 casos de internações por agravos respiratórios no Estado do Pará, sendo 15.762 casos somente na mesorregião Sudeste. Nesse cenário persuasivo, municípios como Conceição do Araguaia, Dom Eliseu, Jacundá, Marabá, Ourilândia do Norte, Redenção, Rondon do Pará, Tucumã, Ulianópolis e Xinguara (PA) responderam por $55 \%$ do total de internações, com uma taxa média de $16,72 \%$ representando os dez municípios com as maiores taxas de morbidade/mil habitantes. 
No mesmo período, também foram registrados 1.933 casos de óbitos por agravos respiratórios no Estado, sendo 278 casos tão somente na mesorregião Sudeste. Atenta-se para municípios como Marabá, Redenção, Paragominas, Parauapebas e Tucuruí (PA), que responderam por $93 \%$ do total de casos, com uma taxa média de $0,40 \%$ representando os 6 municípios com as maiores taxas de óbitos/mil habitantes. Sobreleva-se que, no geral, a taxa de morbidade por DAR para o Estado foi de $9,0 /$ mil habitantes e, para óbitos, foi de $0,24 /$ mil habitantes. Na perspectiva dos grupos de risco, foram registrados no Estado 26.497 casos de morbidade em crianças menores de 5 anos de idade, o que equivale a uma taxa de 34,79 internações/mil habitantes e 10.822 casos em idosos acima de 60 anos de idade, respondendo por uma taxa de 19,7 internações/mil habitantes. Para casos de óbitos por DAR, foram registrados 252 óbitos em menores de 5 anos, com taxa equivalente a 0,33 internações/mil habitantes e 2.092 óbitos em idosos acima de 60 anos, com taxa representativa de 3,81 óbitos/mil habitantes. Esses números reafirmam que o Estado se situa entre os principais da região Norte em situação de risco quanto a problemas de saúde ocasionados por poluentes ambientais, alertando para uma demanda por atenção e por um olhar especial, principalmente para os grupos prioritários.

Conforme cita a FAPESPA (2016), o Governo do Estado do Pará, com base nas composições do Plano Plurianual (PPA) 2016-2019, institucionalizou, ainda em 2015, a divisão do Estado em 12 Regiões de Integração (RI), que, demarcadas por um efeito geopolítico, são detentoras de características específicas e relevantes para a economia. Essa regionalização teve como propósito alvitrar investimentos estruturantes e ações estratégicas condizentes com os problemas regionais, visando facilidades nas negociatas e divisão de recursos igualmente paritários. Desta maneira, observa-se que os 39 municípios que compõem a mesorregião Sudeste paraense são também abrangidos por se enquadrarem territorialmente em 4 RI do Estado, sendo Carajás, Lago do Tucuruí, Araguaia e Rio Capim (Figura 2), aglomerando seus municípios devido a similaridades nas dimensões territoriais e do fator motriz econômico e produtivo regional (SCHUBER; MORAES, 2015).

Figura 2 - Identificação dos municípios do Sudeste paraense divididos por Regiões de Integração (RI) em situações de riscos à exposição da poluição atmosférica.

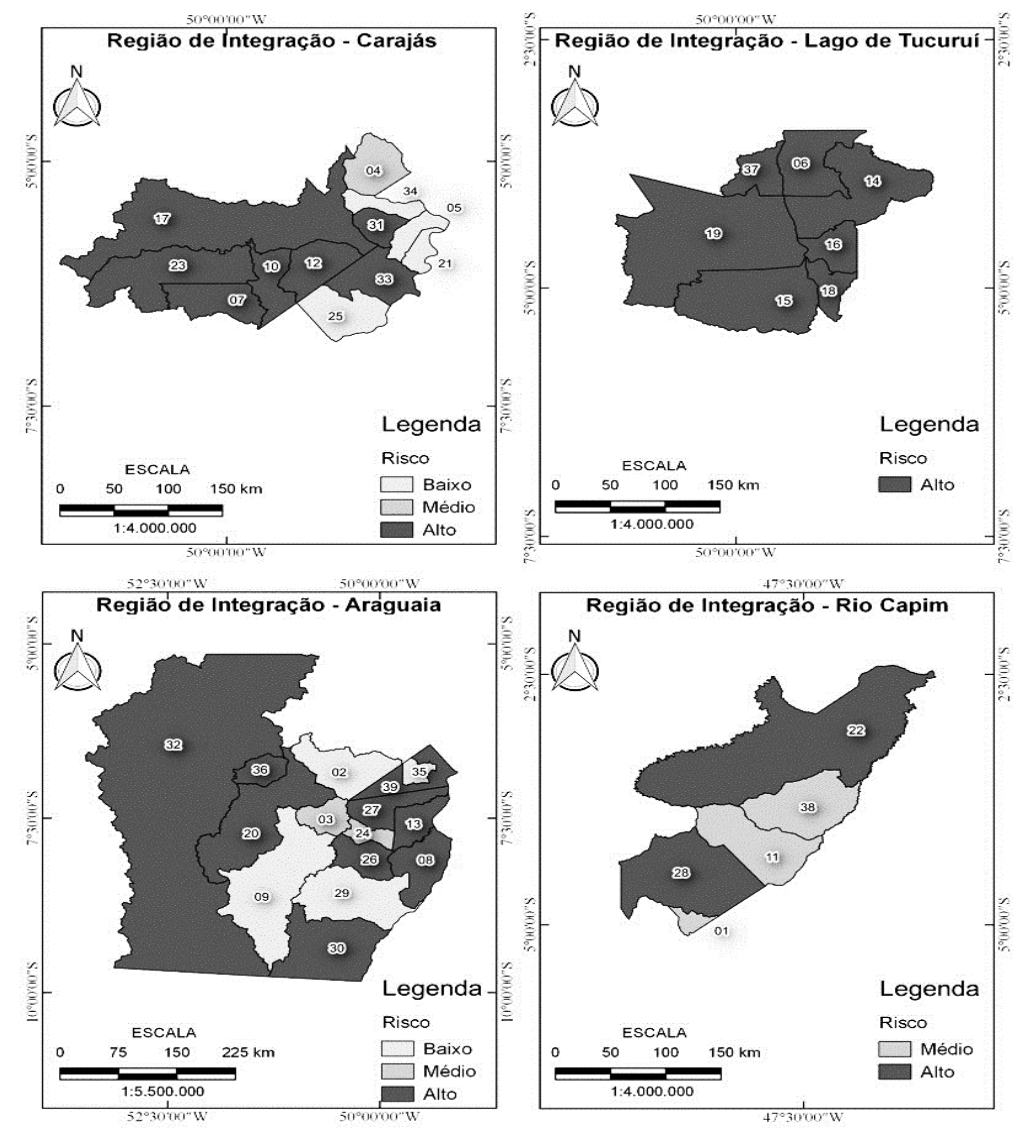

Fonte - Elaborado pelos autores a partir de dados coletados em boletins técnicos e agências governamentais. 
Quanto ao diagnóstico feito para as Regiões de Integração (RI), pode-se destacar algumas características relevantes no que diz respeito aos riscos à saúde. Desta forma, tem-se que a Região de Integração de Carajás é formada por 12 municípios e possui uma população de 626.174 habitantes, 7,7\% da população do Estado do Pará (IBGE, 2010). Dentre esses municípios, 58\% estão em situação de "Alto Risco"; 33\%, em situação de "Médio Risco"; e 9\% estão em condições de "Baixo Risco". Segundo a FAPESPA (2017), a RI Carajás é a maior produtora de minério de ferro do Pará, possui potencial na indústria metalúrgica com fabricação de aço, é destaque na indústria de transformação com a indústria alimentícia e considerada a segunda região de integração na produção bovina $(14 \%)$ e na produção leiteira $(23 \%)$. A RI Carajás tem a terceira menor taxa de mortalidade infantil do Pará, com 15\% (DATASUS, 2017), embora assuma papel de destaque no desmatamento, com área total desmatada de $27.525 \mathrm{~km}^{2} \mathrm{em} \mathrm{2013}$, equivalente a $11 \%$ do desmatamento do Estado e $61 \%$ em relação à área total da RI (INPE, 2017). Nesse cenário, a RI Carajás incumbe-se de extrema importância para o desenvolvimento do Estado, apesar de, contraditoriamente, estar com mais de $50 \%$ dos seus municípios em situações de risco em saúde em decorrência da exposição à poluição atmosférica, muito provavelmente devido à sua forma de ocupação territorial.

Em seguida, a análise feita para a RI Lago do Tucuruí revelou uma população de 394.177 habitantes, representando $5 \%$ da população do Estado do Pará (IBGE, 2010), com 7 municípios pertencentes à mesorregião Sudeste e todos esses (100\%) se qualificando com um status em situação de "Alto Risco" em saúde por exposição à poluição atmosférica. Sob o enfoque do agronegócio, a RI Lago do Tucuruí se destaca pela importância energética, através das operações da Usina Hidrelétrica Tucuruí (Eletrobrás Eletronorte), pelo potencial para a produção de gado de corte com $10 \%$ do rebanho bovino do Estado e possui, dentre as Rls citadas neste estudo, a menor taxa de mortalidade infantil do Estado, com 14\% (DATASUS, 2017). Embora, com esse panorama preocupante em saúde e ambiente, a RI Lago do Tucuruí tenha exibido, em 2013, uma área total desmatada de $22.101 \mathrm{~km}^{2}$, equivalente a $8 \%$ do desmatamento do Estado e $55 \%$ em relação à área total da RI (FAPESPA, 2017).

Logo após, no diagnóstico feito para a RI Araguaia, foi ressaltada uma população de 521.027 habitantes, concebendo 6,4\% da população do Estado (IBGE, 2010). Na análise para as situações de risco à saúde, revelou-se que a RI Araguaia compreende 15 municípios que fazem parte da mesorregião Sudeste paraense e que $60 \%$ destes estão em situação de "Alto Risco"; $26,67 \%$, em "Médio Risco"; e 13,33\%, em "Baixo Risco", justamente por exposição à poluição atmosférica. Em seguida, dados empíricos sociodemográficos posicionam a RI Araguaia como a maior produtora de bovino (38\%) e abacaxi (87\%), bem como a segunda maior produtora de soja (28\%) do Estado do Pará. Ainda a sinalizam como a primeira do ranking na produção leiteira $(33 \%)$ e segunda na produção de milho (23\%), classificando-a como uma RI de grande potencial na produção de níquel, estanho, ouro, potássio e magnésio (FAPESPA, 2017). Segundo o DATASUS (2017), a RI Araguaia preconiza situação de vulnerabilidade social e ambiental ao ser posicionada, nesse cenário, com a segunda maior taxa de mortalidade infantil no Pará, com 18\%, e com uma área total desmatada de $19.963,40 \mathrm{~km}^{2}$ em 2013, equivalente a $25 \%$ do desmatamento do Estado e $37 \%$ em relação à área total da RI (INPE, 2017).

Por fim, nota-se que a maioria dos municípios da RI Rio Capim fazem fronteira com os Estados de Tocantins (TO) e Maranhão (MA). A RI Rio Capim possui 648.913 habitantes, contabilizando $8 \%$ da população do Estado do Pará (IBGE, 2010). Ao mesmo tempo, contorna territorialmente cinco municípios que compõem a mesorregião em estudo. A RI exibiu um panorama preocupante quanto ao risco à saúde em comunidades expostas à poluição atmosférica, tendo $60 \%$ dos municípios classificados em situação de "Alto Risco" e 40\% em "Médio Risco". Essa RI não evidenciou municípios em situação de "Baixo Risco". Repara-se que tal situação em saúde e ambiente pode estar associada ao processo de ocupação de terras e ao cenário de desenvolvimento econômico estabelecido, pois, segundo o Boletim Informativo da FAPESPA (2017), a RI Rio Capim é a maior produtora de grãos $(40 \%)$ e a segunda maior de soja $(50 \%)$ e de milho $(30 \%)$ do Estado do Pará. Vasconcellos e Beltrão (2018) citam que, na fruticultura, ela sobressai com $83 \%$ na produção de laranja, $16 \%$ na de coco, 33\% na de maracujá e 12\% na de mamão; na mineração, pela extração de alto potencial de caulim, que estende operacionalização no município de Ipixuna do Pará, e de bauxita em Paragominas (PA).

Em tal caso, a RI Rio Capim desperta preocupações também para o cenário ambiental, em se tratando da constância de terras nativas e de uma rica biodiversidade, que estão sendo utilizadas para fins comerciais, a grosso modo, em função da ocupação agropecuária, rompendo fronteiras com os outros Estados sem nenhuma preocupação com a preservação ambiental ou mesmo com sua reconstituição florestal. Na área da saúde, o prognóstico revelou que a RI Rio Capim ocupa a terceira menor taxa de mortalidade infantil, com 15\% (DATASUS, 2017). Entretanto, registrou um avanço com 

Jonathan Willian Zangeski Novais

o desmatamento, com uma área total desmatada de $37.886 \mathrm{~km}^{2}$ em 2013 , equivalente a $15 \%$ do desmatamento do Estado e 61\% em relação à área total da RI (INPE, 2017).

\section{Caracterização do perfil dos participantes}

A pesquisa socioparticipativa reuniu 41 participantes, que foram divididos em quatro Grupos de Trabalhos (GTs) conforme os cenários das forças do desenvolvimento econômico da mesorregião. A divisão dos GTs foi feita por meio de sorteio, utilizando a estratégia da caixa de curiosidades, em que foram inseridos copos personalizados com diferentes cores simbolizando cada um dos cenários econômicos.

O GT1, grupo da "mineração", de cor preta, formado por 11 participantes, tinha na sua composição $72,7 \%$ do gênero feminino e $27,3 \%$ do masculino. Dentre os participantes, $55 \%$ declararam ter idade entre 21 e 30 anos e $45 \%$, acima de 30 anos. A média de idade desse grupo foi de 30,81 anos. 0 número de filhos variou entre 1 e 4 filhos, embora $63,6 \%$ informaram não ter filhos. Sobre a religião, $54,5 \%$ informaram ser evangélicos; 36,4\%, católicos; e 9,1\%, cristãos. A maior parte dos entrevistados declarou ter concluído o Ensino Médio (91\%), seguido de 9\% tendo o Ensino Superior. Quanto à renda familiar, $18,2 \%$ dos participantes do GT1 declararam renda de até 1 salário mínimo ( $R \$ 998,00) ; 45,5 \%$, de até 2 salários mínimos; e 36,3\%, acima de 2 salários mínimos.

O GT2, grupo da "produção de energia", de cor azul, formado por 10 participantes, tinha na sua composição $60 \%$ do gênero feminino e $40 \%$ do masculino. Dentre os participantes, $10 \%$ declararam ter idade entre 18 e 20 anos; $70 \%$, entre 21 e 30 anos; e 20\%, acima de 30 anos. A média de idade desse grupo foi de 27,3 anos. O número de filhos variou entre 1 e 4 filhos, embora $20 \%$ declararam ter apenas 1 filho; $20 \%$, de 2 a 4 filhos; e $60 \%$ declararam não ter filhos. A propósito da religião, $50 \%$ informaram ser católicos; $30 \%$, cristãos; e $20 \%$, espíritas. A maior parte dos entrevistados declarou ter concluído o Ensino Médio (60\%), seguido de 10\%, o Ensino Fundamental e 30\%, o Ensino Superior. Quanto à renda familiar, $30 \%$ dos participantes do GT2 declararam renda de até 1 salário mínimo; 30\%, de até 2 salários mínimos; e 40\%, acima de 2 salários mínimos.

O GT3, grupo da "pecuária", de cor vermelha, formado por 10 participantes, tinha na sua composição $50 \%$ do gênero feminino e $50 \%$ do masculino. Dentre os participantes, $20 \%$ declararam ter idade entre 18 e 20 anos; $50 \%$, entre 21 e 30 anos; e 30\%, acima de 30 anos. A média de idade desse grupo foi de 27,2 anos. O número de filhos variou entre 1 e 4 filhos, entretanto, $30 \%$ declararam ter apenas 1 filho; $30 \%$, de 2 a 4 filhos; e $40 \%$ declararam não ter filhos. Sobre a religião, $60 \%$ informaram ser evangélicos; $30 \%$, católicos; e 10\%, cristãos. A maior parte dos entrevistados declarou ter concluído o Ensino Médio (60\%), seguido de 40\% com o Ensino Superior. Quanto à renda familiar, $20 \%$ dos participantes do GT3 declararam renda de até 1 salário mínimo; $40 \%$, de até 2 salários mínimos; e $40 \%$, acima de 2 salários mínimos.

Por fim, o GT4, grupo da "extração de madeira", de cor laranja, formado por 10 participantes, tinha na sua composição $70 \%$ do gênero masculino e $30 \%$ do feminino. Dentre os participantes, $60 \%$ declararam ter idade entre 21 e 30 anos e $40 \%$, acima de 30 anos. A média de idade desse grupo foi de 34 anos. $O$ número de filhos variou entre 1 e 4 filhos, porém, 30\% declararam ter apenas 1 filho; $60 \%$, de 2 a 4 filhos; e 10\% declararam não ter filhos. Sobre religião, $60 \%$ informaram ser católicos; $20 \%$, evangélicos; e $20 \%$, cristãos. A maior parte dos entrevistados declarou ter concluído o Ensino Superior $(60 \%)$, seguido de $20 \%$, o Ensino Fundamental e 20\%, o Ensino Médio. Quanto à renda familiar, $10 \%$ dos participantes do GT4 declararam renda de até 1 salário mínimo; $30 \%$, de até 2 salários mínimos; e 60\%, acima de 2 salários mínimos.

\section{Participação social na avaliação e intervenção sobre os impactos das matrizes econômicas na saúde e no ambiente das comunidades}

Durante a fase de discussão coletiva dos painéis, observou-se que mais de $40 \%$ dos participantes referiu nunca ter participado de espaços deliberativos e colocou como prioridade a necessidade de uma maior inclusão dos representantes sociais, principalmente na tomada de decisão sobre questões relacionadas ao desenvolvimento econômico e a impactos na saúde e no ambiente, pois se sentem desacreditados no discurso político que enfatiza a geração de empregos com a vinda e a instauração destes empreendimentos econômicos. Eles afirmam que problemas associados a estes devem ser discutidos por meio de uma participação social mais representativa. Em decorrência dessas falas, foi possível materializar um modelo alegórico da árvore de problemas para cada uma das forças motrizes citadas neste estudo, baseando-se nas características fundamentadas dos GTs, conforme mostra a Figura 3. 
Vigilância aos efeitos da nova fronteira agrícola: uma análise participativa socioambiental e de risco à saúde das comunidades expostas à poluição atmosférica em áreas de transição de Cerrado-Amazônia, Sudeste do Pará
Thiago Fernandes Sandra de Souza Hacon Jonathan Willian Zangeski Novais

Figura 3 - Modelos propostos das árvores de problemas, construídas por meio das percepções dos atores sociais, a partir da compreensão coletiva sobre os riscos à saúde e ao ambiente quanto à poluição atmosférica, nos diferentes cenários de motricidade econômica no Sudeste paraense, 2019.
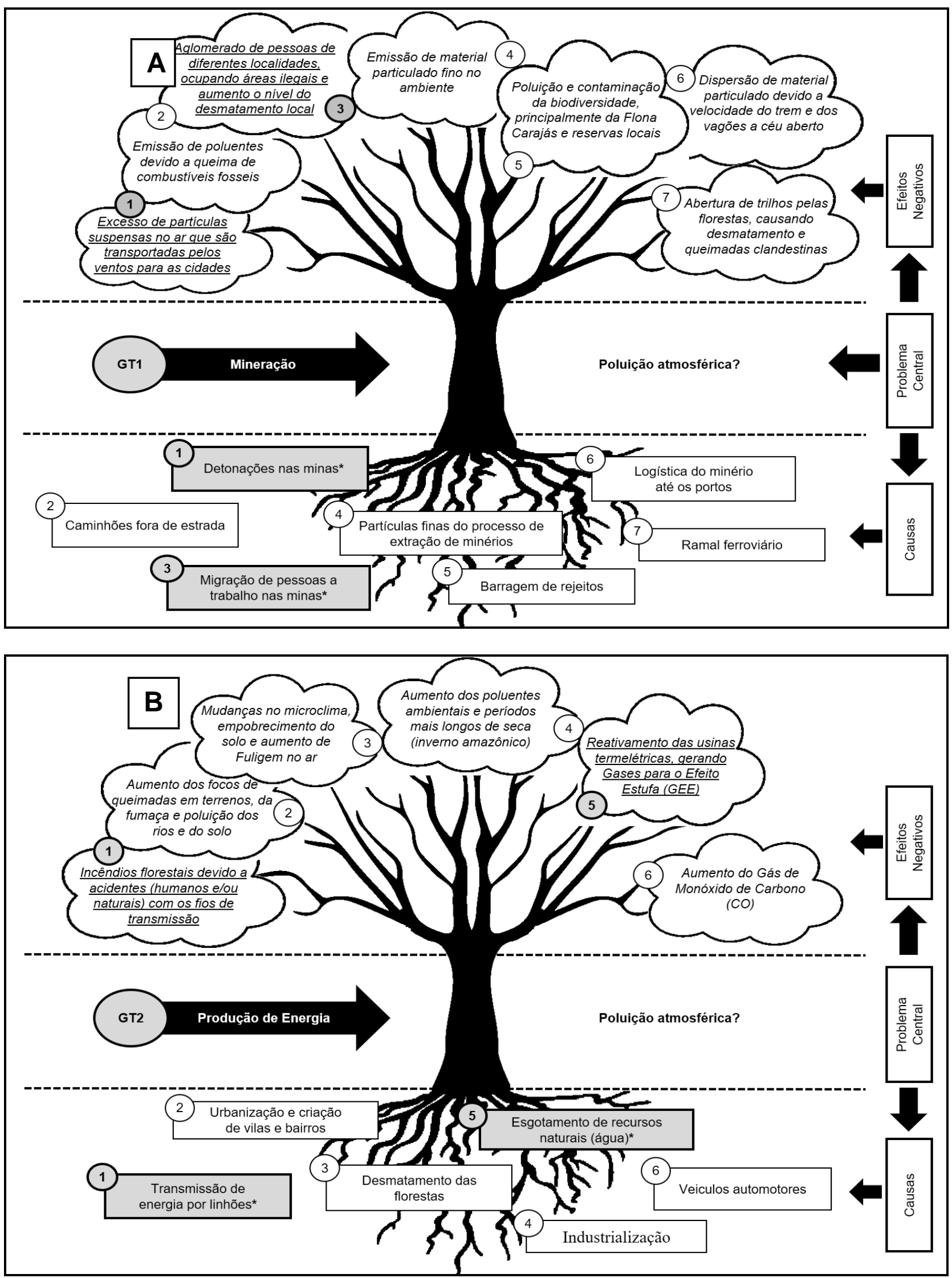

Caminhos de Geografia

Uberlândia-MG $\quad$ v. 21, n. 78

Dez/2020

p. $270-289$

Página 281 
Vigilância aos efeitos da nova fronteira agrícola: uma análise participativa socioambiental e de risco à saúde das comunidades expostas à poluição atmosférica em áreas de transição de Cerrado-Amazônia, Sudeste do Pará
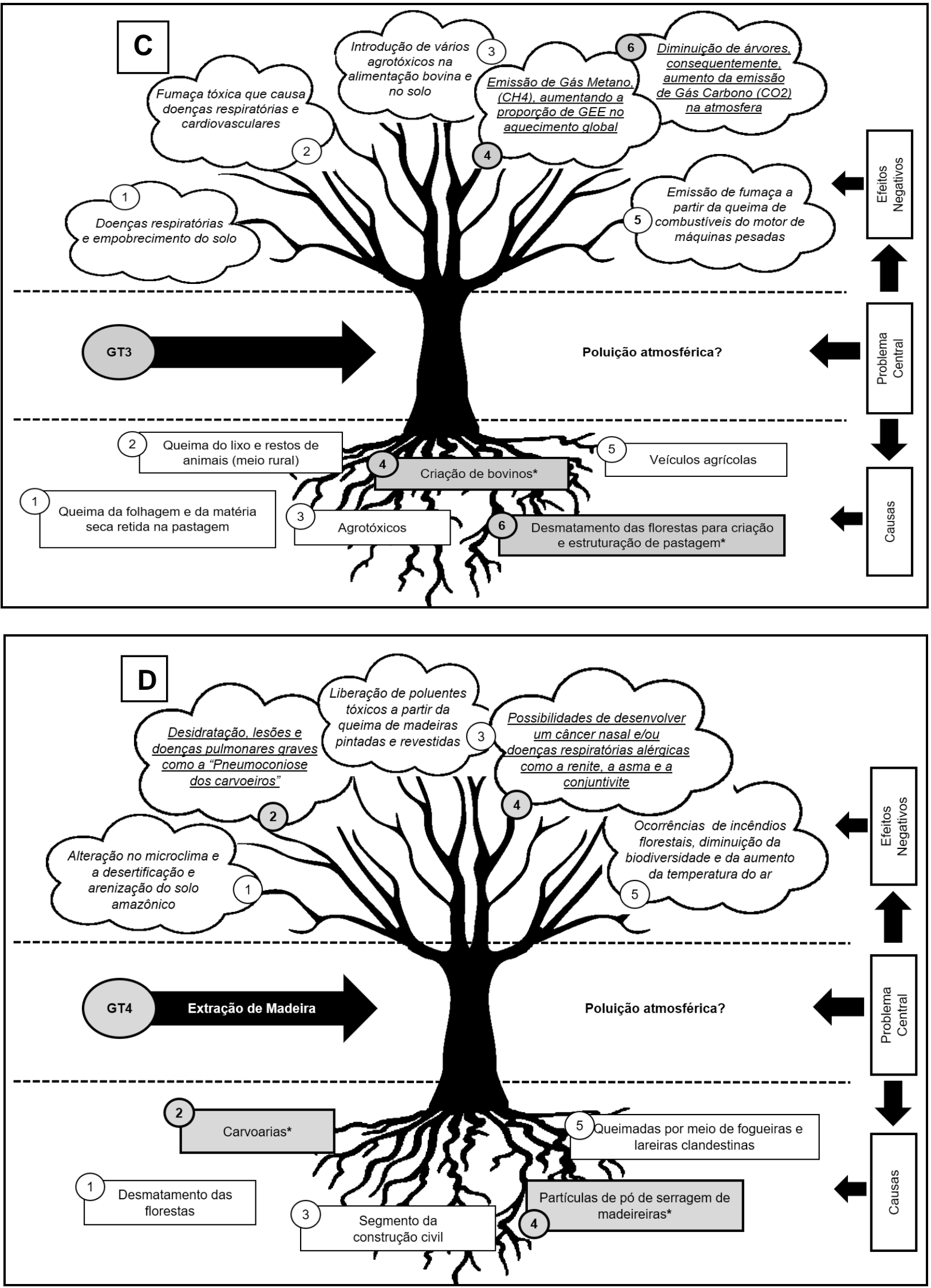

Fonte - Elaborado pelos autores a partir da coleta de dados com os atores sociais, 2019 
Segundo Fernandes e Andrade (2016), as diferentes posições que os atores sociais ocupam no tecido das relações sociais organizam diferentemente os processos simbólicos, pois implicam distintos pontos de ancoragem das representações sociais. Para tanto, é essencial entender a complexidade da estrutura dos problemas ambientais e de saúde e agir com responsabilidade para minimizar as perdas atuais (SANDIFER et al., 2015).

Diante disso, para cada causa-efeito citada em decorrência do cenário motriz de desenvolvimento econômico foram versadas ações de priorização, o que revela a hipótese de emergência quanto à necessidade de criação de políticas públicas básicas ou tão somente, para alguns casos, que sejam respeitadas as leis e diretrizes constituintes para a segurança ambiental e humana. Assim, conforme a priorização dada pelos atores sociais, ao assinalarem com um $\left(^{*}\right)$ as causas e os efeitos de maior representatividade coletiva, associada meramente à problemática da poluição atmosférica e dos agravos à saúde humana, foram relacionadas também as possíveis soluções sobre a percepção social, conforme mostrado no Quadro 1. Dito isso, surgem em conexidade as possíveis soluções, que passam a ser elementos de composição da representação social.

Quadro 1 - Estrutura das soluções de mitigação quanto ao risco da poluição atmosférica na saúde humana, conforme as matrizes econômicas de desenvolvimento, embasados na percepção dos atores sociais que residem, em sua maioria, em municípios de fronteira agrícola - Sudeste paraense.

\begin{tabular}{|c|c|c|}
\hline \multicolumn{3}{|c|}{ GT1: Mineração } \\
\hline Principais Causas* & Efeitos Negativos & Possíveis Soluções \\
\hline $\begin{array}{l}\text { (1) Detonações nas } \\
\text { minas }\end{array}$ & $\begin{array}{l}\text { Excesso de partículas } \\
\text { suspensas no ar que são } \\
\text { transportadas pelos ventos } \\
\text { para as cidades. }\end{array}$ & $\begin{array}{l}\text { Fiscalização quanto às normas de permissão e } \\
\text { segurança na detonação de pedras e do } \\
\text { funcionamento e da manutenção contínua da } \\
\text { barragem do gelado e do complexo Carajás, com a } \\
\text { ampliação dos treinamentos para as comunidades } \\
\text { sitiantes e urbanas em casos de tremores de terras } \\
\text { e/ou de rompimento de barragem. }\end{array}$ \\
\hline $\begin{array}{l}\text { (3) Migração de } \\
\text { pessoas a trabalho nas } \\
\text { minas }\end{array}$ & $\begin{array}{l}\text { Aglomerado de pessoas de } \\
\text { diferentes localidades, } \\
\text { ocupando áreas ilegais, } \\
\text { aumento do nível do } \\
\text { desmatamento local. }\end{array}$ & $\begin{array}{l}\text { Estruturação de um projeto-piloto referente a um } \\
\text { Plano Socioterritorial Urbanístico para a região, } \\
\text { assim, conduzindo democraticamente à divisão de } \\
\text { terras e fiscalizando a construção de loteamentos, } \\
\text { evitando o crescimento populacional urbano para } \\
\text { dentro das florestas e os conflitos sociais. }\end{array}$ \\
\hline \multicolumn{3}{|c|}{ GT2: Produção de Energia } \\
\hline Principais Causas* $^{\star}$ & Efeitos Negativos & Possíveis Soluções \\
\hline $\begin{array}{l}\text { (1) Transmissão de } \\
\text { energia por linhões }\end{array}$ & $\begin{array}{l}\text { Incêndios florestais devido a } \\
\text { acidentes (humanos e/ou } \\
\text { naturais) com os fios de } \\
\text { transmissão. }\end{array}$ & $\begin{array}{l}\text { Monitoramento das redes de distribuição de } \\
\text { energia por meio de satélites ou drones e } \\
\text { manutenção contínua das linhas de transmissão, } \\
\text { através da criação de pontos estratégicos de apoio } \\
\text { e segurança móvel terrestre em casos de incêndios } \\
\text { dessa natureza. }\end{array}$ \\
\hline $\begin{array}{l}\text { (5) Esgotamento de } \\
\text { recursos naturais } \\
\text { (água) }\end{array}$ & 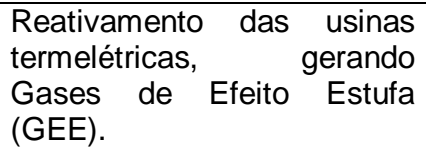 & $\begin{array}{l}\text { Tecnologias ou procedimentos mais eficientes para } \\
\text { filtrar os particulados finos que são emitidos com a } \\
\text { fumaça pelas chaminés durante o processo de } \\
\text { produção de energia. }\end{array}$ \\
\hline \multicolumn{3}{|c|}{ GT3: Pecuária } \\
\hline Principais Causas $^{\star}$ & Efeitos Negativos & Possíveis Soluções \\
\hline (4) Criação de bovinos & $\begin{array}{l}\text { Emissão de gás metano } \\
\left(\mathrm{CH}_{4}\right) \text {, aumentando a } \\
\text { proporção de GEE no } \\
\text { aquecimento global. }\end{array}$ & $\begin{array}{l}\text { Normas e/ou diretrizes que estabeleçam ou } \\
\text { regulamentem o uso de parâmetros para o uso de } \\
\text { aditivos na concentração nutricional da ração dos } \\
\text { bovinos. }\end{array}$ \\
\hline $\begin{array}{l}\text { (6) Desmatamento das } \\
\text { florestas para criação e } \\
\text { estruturação de } \\
\text { pastagem }\end{array}$ & $\begin{array}{l}\text { Diminuição de árvores, } \\
\text { consequentemente, } \\
\text { aumento da emissão de gás } \\
\text { carbono }\left(\mathrm{CO}_{2}\right) \text { na atmosfera. }\end{array}$ & $\begin{array}{l}\text { Fiscalização in loco dos órgãos ambientais } \\
\text { (ICMbio, IBAMA, SEMA e outros) a respeito do } \\
\text { cumprimento do Código Florestal e do seu } \\
\text { comprometimento com o reflorestamento e com as } \\
\text { comunidades, principalmente, nas Unidades de } \\
\text { Conservação. }\end{array}$ \\
\hline \multicolumn{3}{|c|}{ GT4: Extração de Madeira } \\
\hline Principais Causas* $^{\star}$ & Efeitos Negativos & Possíveis Soluções \\
\hline
\end{tabular}

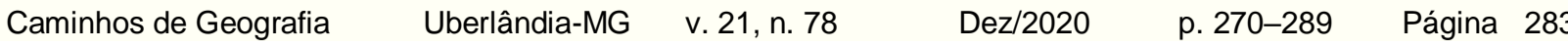




\begin{tabular}{|c|c|c|}
\hline (2) Carvoarias & $\begin{array}{l}\text { Desidratação, lesões e } \\
\text { doenças pulmonares graves } \\
\text { como a "Pneumoconiose } \\
\text { dos carvoeiros". }\end{array}$ & $\begin{array}{l}\text { Fiscalização do trabalho escravo (ou análogo) e } \\
\text { dos níveis de segurança pessoal, bem como a } \\
\text { promoção de campanhas informativas sobre os } \\
\text { riscos à saúde ao inalar a fumaça oriunda da } \\
\text { queima da madeira durante a produção do carvão } \\
\text { vegetal. }\end{array}$ \\
\hline $\begin{array}{l}\text { (4) Partículas de pó de } \\
\text { serragem de } \\
\text { madeireiras }\end{array}$ & $\begin{array}{l}\text { Possibilidade } r \text { de } \\
\text { desenvolver um câncer } \\
\text { nasal e/ou doenças } \\
\text { respiratórias alérgicas como } \\
\text { a rinite, a asma e a } \\
\text { conjuntivite. }\end{array}$ & $\begin{array}{l}\text { Criação de um Fórum Comunitário Municipal para } \\
\text { discutir os impactos causados pelas partículas da } \\
\text { serragem, com o objetivo de estabelecer medidas } \\
\text { regulamentadoras que visem ao monitoramento, à } \\
\text { fiscalização e à diminuição desse particulado, } \\
\text { principalmente, em épocas de estiagem. }\end{array}$ \\
\hline
\end{tabular}

*Principais causas assinaladas pelos atores sociais nos painéis temáticos das árvores de problemas.

Fonte - Elaborado pelos autores a partir de dados coletados com os atores sociais, 2019.

No que tange a medidas de minimização do risco de aumento da poluição atmosférica, os participantes fizeram alusão à necessidade de intervenções políticas, tais como: monitoramento dos linhões de distribuição de energia, flexibilidade na aquisição de alternativas energéticas na Amazônia, fiscalização do trabalho análogo nas carvoarias, tecnologias mais eficientes para filtragem dos particulados finos em automóveis e indústrias, bem como realização e divulgação de estudos de monitoramento dos níveis de poluentes atmosféricos dos municípios fronteiriços agrícolas (HERREIRA; MOREIRA, 2013).

Além disso, registrou-se a constatação da conexão de similitude entre os GTs, que, neste estudo, ressaltou uma maior aproximação cognitiva entre os GTs 2, 3 e 4 . O diagnóstico permite ainda inferir a característica de centralidade de cada GT, o que evidencia ser uma teia representativa dos cenários. $\mathrm{Na}$ análise geral dos painéis, emergiram 418 evocações, com 178 palavras diferentes, com densidade média vocabular de 0,474 e uma frequência média relativa de 0,002, expondo a polissemia dos termos indutores, conforme mostra a Tabela 2.

Tabela 2 - Frequência de evocação e similitude de palavras conforme as RSs para cada um dos cenários motrizes do desenvolvimento econômico, Sudeste paraense, 2019.

\begin{tabular}{|c|c|c|c|}
\hline \multicolumn{2}{|c|}{ GT 1: Mineração } & \multicolumn{2}{|c|}{ GT 2: Produção de Energia } \\
\hline Frequência & Palavras & Frequência & Palavras \\
\hline 4 & Partículas & 7 & Aumento \\
\hline 3 & Gases & 4 & Desmatamento \\
\hline 3 & Emissão & 4 & Queimadas \\
\hline 3 & Veículos & 3 & Empreendimentos \\
\hline 3 & Pessoas & 3 & Linhões \\
\hline \multicolumn{2}{|c|}{ GT 3: Pecuária } & \multicolumn{2}{|c|}{ GT 4: Extração de Madeira } \\
\hline Frequência & Palavras & Frequência & Palavras \\
\hline 4 & Agrotóxico & 4 & Desmatamento \\
\hline 4 & $\operatorname{Ar}$ & 4 & Aumento \\
\hline 4 & Desmatamento & 3 & $\mathrm{Ar}$ \\
\hline 4 & Pastagem & 3 & Serragem \\
\hline 3 & Aquecimento & 3 & Comunidades \\
\hline 3 & Metano & & \\
\hline 3 & Queimadas & & \\
\hline 3 & Gases & & \\
\hline 3 & Poluição & & \\
\hline
\end{tabular}

Fonte - Elaborado pelos autores a partir de dados coletados com os atores sociais, 2019.

Segundo Rochedo et al. (2018), entre 2005 e 2012, o Brasil reduziu suas emissões de Gases de Efeito Estufa (GEE) em 54\%, sobretudo, pela redução do desmatamento em 78\%. De acordo com os autores, a aprovação do Novo Código Florestal Brasileiro, em 2012, provocou um retrocesso gradual

$\begin{array}{lllll}\text { Caminhos de Geografia } \quad \text { Uberlândia-MG } & \text { v. 21, n. } 78 \quad \text { Dez/2020 } & \text { p. 270-289 Página } 284\end{array}$


na governança ambiental, agravada a partir de 2016 com a barganha política promovida pela chamada bancada ruralista para a aprovação de projetos políticos de interesse do Governo Federal.

Novamente, Rochedo (2018) e demais colaboradores citam que, na atual circunstância, será improvável o Brasil honrar com seus compromissos assumidos para ajudar o mundo a cumprir o Acordo de Paris e salientam que reduzir o desmatamento, principalmente na Amazônia Legal, seria de longe a alternativa mais barata e mais vantajosa para alcançar suas metas nacionais e internacionais. Por fim, estabelece que há sérios entraves quanta à participação de comunidades frente às representações em comitês, colegiados e órgãos, o que acarreta um risco iminente nas deliberações, principalmente, em se tratando do atual cenário político, que, com o Decreto Presidencial no 9.759/2019, julga promover a extinção e limita a criação de órgãos e colegiados no Governo Federal. Essa medida, obviamente, revoga a atuação e a participação da população brasileira no monitoramento, na formulação e no fomento de políticas públicas em tantas áreas prioritárias e sensíveis aos cidadãos, diminuindo a representatividade nas tomadas de decisões políticas, sociais e pela luta por direitos humanos.

Ferrante e Fearnside (2019) citam que as ações propostas pelo novo governo e seus apoiadores ruralistas, que inclui a abolição de reservas legais e a abertura de unidades de conservação e terras indígenas à mineração na Amazônia Legal, impactariam florestas, biodiversidade e a vida e identidade dos povos tradicionais, incluindo povos descendentes de escravos, quilombolas, pescadores e ribeirinhos.

\section{CONCLUSÕES}

De acordo com o objetivo do estudo, conclui-se que $64,1 \%$ dos municípios que abrangem a mesorregião Sudeste do Pará estão classificados na situação de "Alto Risco" em saúde e ambiente, com um status de vulneráveis, eminentemente por efeito da poluição atmosférica na saúde humana. $\mathrm{Na}$ descrição situacional da mesorregião, ora subdivida por Regiões de Integração, mostra-se pelos indicadores que a RI Lago do Tucuruí, composta pelos municípios de Breu Branco, Goianésia do Pará, Itupiranga, Jacundá, Nova Ipixuna, Novo Repartimento e Tucuruí, foi a mais afetada, nessa ocasião, em função dos impactos decorrentes da expansão dos setores que impulsionam o agronegócio local, frisando o poderio de mudanças no uso e na ocupação da terra e dos recursos naturais. Dito isso, realça a influência dos grandes empreendimentos hidrelétricos e minerais, sobretudo, com a operacionalização da Usina Hidrelétrica de Tucuruí e com a construção de ferrovias unindo o Estado do Pará (PA) com o Maranhão (MA) e o Tocantins (TO), facilitando o escoamento de produtos e insumos em fomento à nova fronteira agrícola.

Além disso, o processo revelou ausência de representatividade dos atores sociais das localidades estudadas em espaços decisórios sobre a problemática ambiental. A construção em coletividade das árvores de problemas descortinou que há um distanciamento entre as políticas públicas sociais das comunidades. Durante vários momentos de discussões, foram manifestadas pelos participantes as dificuldades no acesso à saúde, principalmente nos municípios em situação de "Alto Risco" e fronteiriços, relatando as disposições com que os sujeitos são recepcionados nas unidades de prontoatendimento, a falta de manutenção em aparelhagem, estradas e a inexistência de fiscalização ambiental somada à má gestão dos recursos públicos e naturais, gerando, assim, uma insatisfação e revolta com o poder público.

Essa contrariedade foi perceptível na fala dos participantes oriundos de municípios arrecadadores de royalties, como é o caso da mineração e das hidrelétricas, em que alegaram desprazer com os serviços básicos prestados pelos governos municipais, principalmente, saúde e segurança. Todavia, foi percebível a exiguidade da representatividade dos atores sociais dos municípios antes citados como fronteiriços, enaltecendo quão momentosa foi a presença destes para a construção de soluções, concedendo os momentos de reflexões para tomada de decisão. Vale ressaltar que as melhorias contínuas nos processos de licenciamento, fiscalização, controle e monitoramento ambiental são necessárias, considerando a dinâmica ambiental e econômica da mesorregião, entretanto, precisam ser feitas com ampla discussão e maturação, envolvendo principalmente esses atores sociais. Por fim, recomenda-se urgir ações educativas com profissionais e moradores dessas comunidades que visem a favorecer a constituição e o fortalecimento de movimentos coletivos, indispensáveis à garantia dos direitos de mitigação das situações de contaminação do ar, de acesso aos serviços de saneamento e de segurança pública e de condições de menor risco à saúde. 


\section{AGRADECIMENTOS}

O presente trabalho foi realizado com apoio da Coordenação de Aperfeiçoamento de Pessoal de Nível Superior (CAPES) - Código de Financiamento 001, da Universidade Federal Rural da Amazônia (UFRA) e da Universidade do Estado de Mato Grosso Carlos Alberto Reyes Maldonado (UNEMAT).

\section{REFERÊNCIAS}

ALMEIDA, A. F.; SOUZA, J. S. A. Dinâmica espaço-temporal de focos de calor em duas terras indígenas do Estado de Mato Grosso: uma abordagem geoespacial sobre a dinâmica do uso do fogo por Xavantes e Bororos. Floresta e Ambiente, Rio de Janeiro, RJ, v. 23, n. 1, p. 1-10, 2016. DOI: http://dx.doi.org/10.1590/2179-8087.041813

AUGUSTO, L. G. S.; FLORÊNCIO, L.; CARNEIRO, R. M. Pesquisa (ação) em saúde ambiental: contexto, complexidade e compromisso social. 3a . ed. Recife: Editora Universidade Federal de Pernambuco, 2003.

BECKER, B. K. Novas territorialidades na Amazônia: desafio às políticas públicas. Boletim do Museu Paraense Emílio Goeldi. Ciências Humanas, Belém, PA, v. 5, n. 1, p. 17-23, 2010.

BRASIL - Diário Oficial da União (DOU). Decreto no 9.759, de 11 de abril de 2019. Extingue e estabelece diretrizes, regras e limitações para colegiados da Administração Pública Federal. BrasíliaDF, 2019.

BRASIL - Ministério da Saúde (MS). Política Nacional de Vigilância em Saúde (PNVS). Boletins epidemiológicos. Brasília-DF, 2010.

- Ministério da Saúde (MS). Vigilância em Saúde de Populações Expostas a Contaminantes Químicos (VIGIPEQ). Boletins epidemiológicos. Brasília-DF, 2012.

- Ministério da Saúde (MS). Vigilância em Saúde de Populações Expostas a Poluição Atmosférica - VIGIAR. Instrumento de Identificação dos Municípios de Risco/IIMR. Situação dos Estados brasileiros. Brasília-DF, 2017.

BRITO, E. P.; SILVA, S. S. POR ENTRE OS CASTANHAIS: Sujeitos e lugares no povoado fortaleza em São Geraldo do Araguaia, Pará. Caminhos de Geografia, Uberlândia, MG, v. 21, n. 73, p. 415428, 2020. DOI: https://doi.org/10.14393/rcg217349450

CETESB - Companhia Ambiental do Estado de São Paulo. Qualidade do ar no Estado de São Paulo-SP, 2012. Disponível em: http://www.cetesb.sp.gov.br/ar/qualidade-do-ar/31-publicacoes-erelatorios Acesso em 16 abril 2019.

COSTA, L. C. A.; SANTOS, A. K. R.; REIS, F. D. Manual de instruções: Instrumento de Identificação dos Municípios de Risco - IIMR. Ministério da Saúde, Brasília-DF. 2014.

COSTA, A. L. S.; REIS, L. R. A contribuição da APA Triunfo do Xingu para o ordenamento fundiário na região da Terra do Meio, Estado do Pará. Amazonian Journal of Agricultural and Environmental Sciences, Belém, PA, v. 60, n. 1, p. 96-102, 2017. DOI: http://dx.doi.org/10.4322/rca.60105

COUTINHO, M. P.; DO BÚ, E. A técnica de associação livre de palavras sobre o prisma do software tri-deux-mots (version 5.2). Revista Campo do Saber, Paraíba, PB, v. 3, n. 1, 2017.

DATASUS - Departamento de Informática do SUS. Epidemiológicas e morbidades para o Estado do Pará e seus municípios. 2017. Ministério da Saúde, Brasília-DF, 2017.

DENATRAN - Departamento Nacional de Trânsito do Estado do Pará. Frota detalhada de veículos automotivos nos munícipios paraenses. 2017. Belém, PA. Disponível em: http://www.detran.pa.gov.br/index .php Acesso em 02 abril 2019.

FAO - Organização das Nações Unidas para Alimentação e Agricultura . El estado de la inseguridad alimentaria en el mundo 2010. La inseguridad alimentaria en crisis prolongadas. Roma: FAO; 2010.

FAPESPA - Relatórios e estatísticas anuais das 12 Regiões de Integração do Pará. 2016. Belém, PA. Disponível em: http://www.fapespa.pa.gov.br/ Acesso em 02 março 2019. 
Relatórios e estatísticas anuais da indústria extrativista dos municípios do Pará. 2017. Belém, PA. Disponível em: http://www.fapespa.pa.gov.br/ Acesso em 02 março 2019.

FERNANDES, J. S. G.; ANDRADE, M. S. Representações sociais de idosos sobre velhice. Arquivos Brasileiros de Psicologia, Rio de Janeiro, RJ, v. 68, n. 2, p. 48-59, 2016. Disponível em: http://pepsic.bvsalud.org/pdf/arbp/v68n2/v68n2a05.pdf Acesso em 07 ago. 2019.

FERRANTE, L.; FEARNSIDE, P. M. Brazil's new president and 'ruralists' threaten Amazonia's environment, traditional peoples and the global climate. Environmental Conservation, page 1 of 3 . 2019. DOI: https://doi.org/10.1017/S0376892919000213

FIAN International; Rede Social de Justiça e Direitos Humanos;Comissão Pastoral da Terra (CPT). Os custos ambientais e humanos do negócio de terras: o caso do MATOPIBA, Brasil. WillyBrand-Platz, Heidelberg, Alemanha. 2017. [Traduzido em Português].

FONSECA, A.; JUSTINO, M.; CARDOSO, D.; RIBEIRO, J.; SALOMÃO, R.; SOUZA C.; VERÍSSIMO, A. Boletim do desmatamento da Amazônia Legal (julho 2019) SAD (p. 1). Belém, PA, Imazon. 2019.

FONSECA-MORELLO, T.; RAMOS, R.; STEIL, L. A. R. A.; PARRY, L. U.; BARLOW, J.; MARKUSSON, N. I. L. S.; FERREIRA, A. Queimadas e incêndios florestais na Amazônia brasileira: porque as políticas públicas têm efeito limitado. Ambiente \& Sociedade. São Paulo, SP, v. 20, n. 4, p. 19-40, 2017. DOI: http://dx.doi.org/10.1590/1809-4422asoc0232r1v2042017

FREITAS, C. U. D.; JUNGER, W.; LEON, A. P. D.; GRIMALDI, R.; SILVA, M. A. F. R.; GOUVEIA, N. Poluição do ar em cidades brasileiras: selecionando indicadores de impacto na saúde para fins de vigilância. Epidemiologia e Serviços de Saúde, v. 22, n. 3, p. 445-454, 2013. DOI: http://dx.doi.org/10.5123/S1679-49742013000300009

HABERMANN, M.; MEDEIROS, A. P. P.; GOUVEIA, N. Tráfego veicular como método de avaliação da exposição à poluição atmosférica nas grandes metrópoles. Revista Brasileira de Epidemiologia, São Paulo, SP, v. 14, p. 120-130, 2011. DOI: https://doi.org/10.1590/S1415-790X2011000100011

HERRERA, J. A.; MOREIRA, R. P. Resistência e conflitos sociais na Amazônia paraense: a luta contra o empreendimento hidrelétrico de Belo Monte. CAMPO-TERRITÓRIO: revista de geografia agrária, Uberlândia, MG, v. 8, n. 16, 2013.

IBGE - Instituto Brasileiro de Geografia e Estatística. Características da população e dos domicílios: resultados do universo. 2010. Rio de Janeiro, RJ: IBGE, 2011.

- Estimativa dos resultados preliminares do censo agropecuária brasileiro: resultados do universo. 2017. Rio de Janeiro, RJ: IBGE, 2018.

INPE - Instituto Nacional de Pesquisa Espacial. Focos de calor: banco de dados de focos de calor e queimadas - Estado do Pará e seus municípios. 2017. Disponível em: http://queimadas.dgi.inpe.br/queimadas/portal-static/estatisticas estados/ Acesso em 05 abril 2019.

Série histórica de dados de queimadas. 2018. Disponível em: http://queimadas.dgi.inpe.br/queimadas/portal-static/estatisticas paises/ Acesso em 12 abril 2019.

LOBATO, M. M.; EMMI, M. F. MIGRAÇÃO NA FRONTEIRA: um encontro de trajetórias sociais em Marabá-Pará. Caminhos de Geografia, v. 15, n. 51, 2014.

LOEWENSON, R. Evaluating intersectoral processes for action on the social determinants of health: learning from key informants. Debates, Policy \& Practice, case studies Geneva: World Health Organization; 2013.

LOPES, C. V. A.; ALBUQUERQUE, G. S. C. Agrotóxicos e seus impactos na saúde humana e ambiental: uma revisão sistemática. Saúde em Debate, Rio de Janeiro, RJ, v. 42, p. 518-534, 2018. DOI: http://dx.doi.org/10.1590/0103-1104201811714

MARINHO, F.; PASSOS, V. M. A.; FRANÇA, E. B. Novo século, novos desafios: mudança no perfil da carga de doença no Brasil de 1990 a 2010. Epidemiologia e Serviços de Saúde, v. 25, p. 713-724, 2016. DOI: https://doi.org/10.5123/s1679-49742016000400005

MENDES, A. (Org.). Amazônia, terra e civilização: uma trajetória de 60 anos. $2^{a}$. ed. Belém, PA: Banco da Amazônia, 2004. v. I e II. 
MONIZ, M. A.; SABÓIA, V. M.; CARMO, C. N. D.; HACON, S. S. Diagnóstico participativo socioambiental e de riscos à saúde das comunidades do entorno do Complexo Petroquímico do Rio de Janeiro, Brasil. Ciência \& Saúde Coletiva, Rio de Janeiro, RJ, v. 22, p. 3793-3806, 2017. DOI: https://doi.org/10.1590/1413-812320172211.23852015

MONTEIRO, M. A. Meio século de mineração industrial na Amazônia e suas implicações para o desenvolvimento regional. Estudos avançados, São Paulo, SP, v. 19, n. 53, p. 187-207, 2005. DOI: https://doi.org/10.1590/S0103-40142005000100012

MOSCOVICl, S. Representações sociais: investigações em psicologia social. 8a․ ed. Petrópolis, RJ: Vozes, 2011. 251 p.

MOURA, S. G.; FILHA, M. D. O. F.; MOREIRA, M. A. S. P.; SIMPSON, C. A.; TURA, L. F. R.; SILVA, A. O. Representações sociais sobre terapia comunitária integrativa construídas por idosos. Revista Gaúcha de Enfermagem, Porto Alegre, RS, v. 38, n. 2, 2017.

MTE - Ministério do Trabalho e Emprego. Relação Anual de Informações Sociais (RAIS) dos municípios brasileiros. 2017. Disponível em: http://trabalho.gov.br/index.php/rais Acesso em 02 abril 2019.

NASCIMENTO, A. P.; SANTOS, J. M.; MILL, J. G.; DE SOUZA, J. B.; JÚNIOR, N. C. R.; REISEN, V. A. Associação entre concentração de partículas finas na atmosfera e doenças respiratórias agudas em crianças. Revista de Saúde Pública, São Paulo, SP, v. 51, p. 3-3, 2017. DOI: https://doi.org/10.1590/s1518-8787.2017051006523

OMS - Organização Mundial de Saúde. Relatório Mundial da Saúde. Determinantes Sociais e Riscos para a Saúde, Doenças Crônicas Não Transmissíveis e Saúde Mental. Brasília-DF, 2018.

PAHO - PAN AMERICAN HEALTH ORGANIZATION. An assessment of health effects of ambient air pollution in Latin America and the Caribbean. Washington D.C: PAHO, 2005.

PEREIRA, C. N.; PORCIONATO, G. L.; CASTRO, C. N. Aspectos socioeconômicos da região do Matopiba. Boletim regional, urbano e ambiental, Brasília, DF, jan-jun. 2018.

PEREIRA, C. N.; CASTRO, C. N.; PORCIONATO, G. L. Dinâmica econômica, infraestrutura e logística no Matopiba. Texto para discussão, Instituto de Pesquisa Econômica Aplicada - IPEA, Brasília, abril de 2018.

PEREIRA, L. I.; PAULI, L. O processo de estrangeirização da terra e expansão do agronegócio na região do Matopiba. Campo-Território: Revista de Geografia Agrária, Minas Gerais, MG, v. 11, n. 23 jul., 2016. DOI: https://doi.org/10.14393/RCT112307

PERES, W. L.; LIRA, O. F. C.; ALMEIDA, N. N.; SANTOS, W. S.; SOUZA, A. L. F. de. Aplicação do Instrumento de Identificação dos Municípios de Risco - IIMR/MS para caracterização do risco dos municípios do Estado de Mato Grosso. Boletim informativo da Secretaria de Estado de Saúde de Mato Grosso. Ministério da Saúde, Brasília-DF, 2009.

PINTO, J. G.; GARAVELLO, M. E. P. E. Transformação (agri)cultural ou etnossustentabilidade: relato de uma aldeia Bororo. Agroecologia e Desenvolvimento Rural Sustentável, Porto Alegre, RS, v. 3, p. 54-60, 2002.

PITTA, F. T.; VEGA, G. C. Impactos da expansão do agronegócio no Matopiba: comunidades e meio ambiente. 1. ed. Rio de Janeiro, RJ: Mórula, 2017.

PORTO, M. F. S. Uma ecologia política dos riscos: princípios para integrarmos o local e o global na promoção da saúde e da justiça ambiental. 2. ed. Rio de Janeiro, RJ: Editora Fiocruz, 2012.

ROCHEDO, P. R.; SOARES-FILHO, B.; SCHAEFFER, R.; VIOLA, E.; SZKLO, A.; LUCENA, A. F.; RATHMANN, R. The threat of political bargaining to climate mitigation in Brazil. Nature Climate Change, v. 8, n. 8, p. 695, 2018. DOI: https://doi.org/10.1038/s41558-018-0213-y

SANDIFER, P. A.; SUTTON-GRIER, A. E.; WARD, B. P. Exploring connections among nature, biodiversity, ecosystem services, and human health and well-being: Opportunities to enhance health and biodiversity conservation. Ecosystem Services, v.12, April 2015, Pages 1-15. DOI: https://doi.org/10.1016/j.ecoser.2014.12.007 

Jonathan Willian Zangeski Novais

SANTOS, L. J. L. Boletim informativo VIGIAR - Pará. Programa Vigilância de Populações Expostas a Poluição Atmosférica. Ministério da Saúde. Brasília, 2013. Disponível em: http://portalarquivos2.saude.gov.br/images/pdf/2017/agosto/30/Par--.pdf Acesso em 29 março 2019.

SANTOS, V. M. A ECONOMIA DO SUDESTE PARAENSE: evidências das transformações estruturais. 1 ${ }^{a}$. ed. Rio de Janeiro, RJ: Editora Ipea, 2017.

SCHUBER, E. S. M.; DE MORAES, S. C. Desenvolvimento Regional do Tapajós: Um Olhar Sob o Cenário Socioeconômico na Região de Integração do Tapajós. Revista de Estudos Sociais, CuiabáMT, v. 17, n. 34, p. 93-111, 2015.

SERAPIONI, M. Os desafios da participação e da cidadania nos sistemas de saúde. Ciência \& Saúde Coletiva, Rio de Janeiro, RJ, v. 19, p. 4829-4839, 2014. DOI: https://doi.org/10.1590/1413$\underline{812320141912.02292013}$

SILVA, A. A.; MIZIARA, F. Avanço do setor sucroalcooleiro e expansão da fronteira agrícola em Goiás. Pesqui. Agropecu. Trop. [online], Goiás, GO, 2011, v.41, n.3, pp.399-407. DOI: http://dx.doi.org/10.5216/pat.v41i3.11054

SILVA, F.; SILVA, L. de J. M. História regional e participação social nas mesorregiões paraenses. Boletim anual do Naea-UFPA, n. 226, dez./2008. Belém, PA, 2008.

VASCONCELLOS, R. C.; BELTRÃO, N. E. S. Avaliação de prestação de serviços ecossistêmicos em sistemas agroflorestais através de indicadores ambientais. Interações, Campo Grande, MS, v. 19, n. 1, p. 209-220, 2018. DOI: https://doi.org/10.20435/inter.v19i1.1494

VILLARDI, J. W. R. A vigilância em saúde ambiental no Brasil: uma reflexão sobre seu modelo de atuação: necessidades e perspectivas. $166 \mathrm{f}$. Tese (Doutorado em Saúde Pública) - Escola Nacional de Saúde Pública Sérgio Arouca. Rio de Janeiro - RJ, 2015.

XAVIER, C. V.; PITTA, F. T.; MENDONÇA, M. L. Monopólio da produção de etanol no Brasil: a fusão Cosan-Shell. São Paulo: Rede Social de Justiça e Direitos Humanos, Editora Outras Expressões, 2011. Disponível em: https://www.social.org.br/revistacosanshel.pdf Acesso em 02 abril 2019.

Recebido em: 24/03/2020

Aceito para publicação em: 09/09/2020 